\title{
Research on the Transferring of Surplus Rural Labor Force
}

\author{
Xiaoming Qiao \\ Journal Editorial Department, Yunnan Normal University, Kunming, \\ Yunnan, 650092
}

\begin{abstract}
China is the country of largest rural population as well as the largest number of surplus rural labor force in the world. What the measure to accelerate the transfer of surplus rural labor force increasingly becomes the key issue of our reformation. This article brings forward the ways of how to transfer the surplus rural labor force through quoting the theory on the transfer of surplus rural labor force and analyzing the influencing factors in the transferring process of surplus rural labor force.

Keywords: Surplus Rural Labor Force; Transfer; Influencing Factors; Ways
\end{abstract}

\section{Introduction}

For a long time, the existence of rural surplus labor force has seriously restricted the development of rural economy and become an important factor affecting peasants' income, agricultural production and rural development. Therefore, the transfer of rural surplus labor is the inevitable economic and social development. In this paper, it is of great practical significance to study and explore the ways to realize the orderly transfer of rural surplus labor force by analyzing the influencing factors in the process of rural labor force transfer. 


\section{The rural surplus labor force understanding}

The so-called rural surplus labor force refers to the part of the labor force which exceeds the demand of rural industry. The essence is that many peasants are in the state of unemployment and semi-unemployment. According to the National Bureau of Statistics released in February 2006, "2005 National Economic and Social Development Statistics Bulletin" [1] shows that in 2005 Chinese rural population of 745.44 million, accounting for $57 \%$ of the population, while the rural labor force of 484.94 million, accounting for The proportion of the total labor force is about $63.9 \%$. From the reality of agriculture, Chinese current rural surplus labor force is about 150 million, the rural surplus labor situation is grim.

The emergence of agricultural surplus labor force is the result of the development of productive forces, agricultural economic development, a byproduct of agricultural progress, we need to work hard to resolve. There are two ways to solve this problem: one is to control the growth rate of the rural population; the other is to speed up the transfer of the surplus labor force in agriculture, which is the key to speed up the transfer of surplus agricultural labor force.

In addition, the rural surplus labor force in the transfer process, there is a considerable degree of blindness in the way, the transfer of personnel is still spontaneous, which also brings a lot of problems. Therefore, the reasonable and orderly transfer of rural surplus labor is the key to realize the sustainable development of agriculture, and it is an important work to optimize the rural resource allocation and the development of social progress and economic stability.

\section{The rural surplus labor transfer theory}

On the issue of rural surplus labor transfer, domestic and foreign economists and scholars have made a lot of discussion, domestic scholars have done a lot of useful research on this issue. Summarize the research of domestic and foreign scholars, the transfer of rural surplus labor can be summarized as the following four theoretical models.

\subsection{Push-pull theory}

This theory holds that the reason for the transfer of labor is the result of the thrust or repulsion of the place of origin and the pull or attraction of the place of transfer. Such as the reduction of cultivated land, deterioration of the environment and limited development prospects, are the thrust factors; and the higher income level, good quality of life and more opportunities for education, etc., is a pull factor.

\subsection{Cost-effectiveness theory}

This theory suggests that labor transfer is a form of human capital investment, and only the expected transfer of labor income is greater than the transfer cost, its 
transfer between industries or regions will occur. The expected return here refers to the transfer of the expected transfer after the more income can be obtained, and transfer costs include monetary and non-monetary costs, the former refers to the transport, housing, food and other expenses, the latter refers to the transfer When reducing the income and high pressure caused by psychological costs.

\subsection{Dual economic development theory}

The theory is that developing countries' economies are made up of two distinct sectors, the traditional and modern sectors. In the traditional agricultural sector, where there are a large number of surplus labor with marginal productivity close to zero or zero, the industrial sector can obtain unlimited labor supply at a low fixed wage level above the subsistence level of the agricultural sector, The rate of labor migration will depend on the rate of profit growth and capital accumulation in the industrial sector.

\subsection{Expected income difference theory}

This theory is formed on the basis of the traditional income difference theory. The traditional theory of income disparity suggests that, because of the difference in productivity between different sectors or regions, the labor force in the lowproductivity sector or region moves to higher income sectors or regions in pursuit of higher incomes, However, the expected income differential theory suggests that the main reason for determining surplus agricultural labor into urban or nonagricultural industries is not the simple income gap, but the expected income gap, the greater the difference, the greater the influx of labor.

\section{Chinese rural surplus labor force transfer factors and method}

Although the above theory of labor force transfer has a certain degree of onesidedness, but the reasonable composition is still the majority, this paper will combine the above theories and analyze the influence factors in the transfer process of rural surplus labor force from the most general point of view , From the source of ideas to consider, put forward some viable ways.

\subsection{Chinese rural surplus labor force transfer factors}

The macroeconomic policies that affect the transfer of rural surplus labor are generally the following: land policy, household registration system, social security system and labor market policy. Each policy formulation and implementation will have a profound impact on the rural economy and society.

It can be said that the household registration system has the most direct impact on the transfer of rural surplus labor force in China. Since the founding of the $\mathrm{PRC}$, China is the implementation of dual household registration system, living in the city for the non-agricultural household registration account in the city, in rural 
areas is the agricultural account. The shortcomings of the current household registration system in coordinating the balanced development between Chinese regions, promoting the transfer of rural surplus labor force, accelerating the modernization of our country's agriculture and ultimately raising the people's living standard have become increasingly prominent. Under the dual household registration system, the farmers' transfer cost is too high, and the other system derived from the dual household registration system leads to the serious unfairness of urban and rural labor force employment and the imbalance of urban and rural economic development. The dual structure of economic development, in turn, Labor is further stranded in rural areas. The current household registration system has seriously affected the enthusiasm of rural migrant workers to enter the cities and towns and the orderly transfer of rural surplus labor force. It also delayed the process of urbanization and the stability of rural society.

Chinese social security system based on the household registration system also has a typical duality. Since 1998, China has established laws and regulations on pension insurance and medical insurance for urban workers. Compared with the urban social security system, the social security of rural residents is relatively incomplete and lacks corresponding legislation, especially in some povertystricken areas. Due to the lack of corresponding legal protection, it is very difficult to realize the social security work of migrant workers, which is the root cause of the phenomenon of social security rights and interests.

However, the present dual social security system in our country has promoted the transfer of rural surplus labor force to a certain extent. The great difference of social security benefits between rural and urban areas plays a certain role in the transfer of rural labor force, and the last protection function of the land owned by farmers But also to a certain extent, promote the transfer of rural surplus labor.

Chinese labor market segmentation for rural labor transfer to the city set up a lot of institutional barriers, hinder the process of transfer of rural surplus labor force, but also forced the units and departments do not absorb or absorb less migrant workers, and labor mobility service system and intermediary organizations But also a serious lag, the relative lack of information, leading to rural labor flow blindly, suffered losses. It can be said that Chinese rural surplus labor mobility is almost entirely in an unorganized and disorderly state [2].

The obstacles to the quality of rural labor force are the important factors that restrict the quantity of surplus labor force, especially the level of transfer. In the course of agricultural modernization, peasants are bound to go to the market, and peasant's own quality directly affects peasants' competitiveness in the market economy.

Chinese agricultural surplus labor force a large number, but the cultural level is not high, the technical quality is low, management, legal and other qualities are quite low. The transfer of rural labor force quality is relatively high relative to the non-transferred part, but the overall social point of view is relatively low, but also continue to show a downward trend [3]. At present, the number of illiterates and semi-illiterates in Chinese rural areas is as high as 300 million. In rural areas, $20.7 \%$ are illiterate and semi-literate, $38.8 \%$ are primary school students, and only $5 \%$ are vocational educators and trainers. Due to the low quality of the rural 
labor force, the rural labor force can only engage in low-level jobs, wages and relatively low. With the adjustment of economic structure, the upgrading of industrial structure and the rapid development of the tertiary industry in China, not only created a huge employment opportunities, but also set a higher threshold of market access, cultural and technical requirements are higher Of the industry and more and more jobs, blocking the transfer of rural surplus labor force road [4]. Moreover, when the relatively high-quality labor force in the rural areas is transferred to the cities, most of them can only be deposited in the low-quality labor force, and the low-quality labor force is retained in the countryside, resulting in low-quality human resources both at the same time. situation. This situation can not meet the breadth and depth of agriculture to develop the needs of the city can not meet the social needs of large-scale production.

\section{2 Chinese rural surplus labor transfer approach}

The transfer of rural surplus labor force is an inevitable requirement of the objective law of human social economic development. In today 's developed capitalist countries, although the transfer model is different, but without exception, experienced the transfer of rural surplus labor in the historical process. After World War II, many developing countries in the world are also varying degrees of rural surplus labor transfer process. At present and in the future for a long period of time, to solve China 's agricultural surplus labor employment is the main way to promote agricultural industrialization, the development of small towns, improve the quality of agricultural labor force.

Promoting agricultural industrialization can effectively improve the quality of agricultural products, greatly increase the added value of agricultural products and promote the export of agricultural products, which can effectively expand Chinese employment space. After Chinese accession to the WTO, China has lost its comparative advantage in resource-intensive products such as grain. To this end, first of all, to adjust the production of grain and grain crops and other crops in the production of labor, the proportion of people continue to engage in agricultural farming personnel can concentrate on the depth of the development of agriculture to improve the multiple cropping index at the same time, the land intensive ,reduce manufacturing cost. Second, under the conditions of agricultural industrialization, in order to improve the commodity rate of agricultural products, some farmers need to be separated from the field of agricultural production, specializing in the production of information and capital supply, technical information services, and product sales, Processing, storage and other prenatal, middle and post-natal services to achieve multi-level value-added agricultural products and surplus labor force multi-channel employment.

Thus, the industrialization of agriculture to the agricultural industry with the second and tertiary industry economic activities together into one, to achieve the rural areas of specialized production, serialization of processing and social services, thereby enhancing the commercialization of agriculture and the level of modernization. And the emergence of a large number of technical service institutions, will force the rural vocational education and technical training onto 
the formal, slow down the labor force into the field of employment time, from the overall inhibition of labor supply.

The characteristics of small towns' "rural first city tail" determine their unique role in absorbing rural surplus labor force. Small cities and towns are the bridge and link between urban and rural areas, suitable for the development of laborintensive small and medium enterprises, large and medium-sized city production to small towns, as well as rural village industry to small towns, for rural labor employment provides a broad Space, can increase the employment opportunities of farmers, promote the development of local rural services. In addition, the chain of agricultural industry to extend the city, in the agricultural and processing industry to form the industrial chain, through the close distance wholesale, retail, help reduce transaction costs.

The technical content of small towns and the organic composition of capital are far lower than those of large and medium-sized cities. The employment costs and urban infrastructure costs for housing labor are much lower than those for large and medium-sized cities; the cost of living in small towns is relatively low; Small cities and towns to enter the threshold is not high, can be strong, and relatively small towns, a more complete infrastructure and urban functions, is conducive to improving the quality of life of rural residents, for these residents, from a psychological point of view is easy and willing to accept.

\section{References}

[1] National Bureau of Statistics of the People's Republic of China. Statistical Communique on National Economic and Social Development, http://tjj.tengzhou.gov.cn/ZYLM/tjgb/tjgb/gj/2005.htm

[2] Chen Liuqin. Rural surplus labor transfer and rural urbanization. Journal of Chongqing Technology and Business University, 9(1), pp. 35-41, 2006

[3] Cheng Dongmin, Lu Guohong. The transfer of rural surplus labor force in China. Journal of Shandong Youth Administrative Cadres College, 11(2), pp. 12 23, 2015

[4] Cai Hongying. Rural urbanization: the fundamental way to transfer the rural surplus labor force in China. Hubei Rural Finance Research, 5(2), pp. 49-52, 2005

[5] Yao Chuanjiang. The choice of road of agricultural surplus labor force transfer. Agricultural Economics, 9(1), pp. 35-41, 2009

[6] Feng Wei. Agricultural surplus labor force in China. Population and Economy, 12(2), pp. 22-24, 2011 